\title{
Seismo-acoustic location method for small-magnitude surface explosions
}

\author{
Il-Young Che, Jin Soo Shin, and Ik Bum Kang \\ Earthquake Research Center, Korea Institute of Geoscience and Mineral Resources, Daejeon, Korea
}

(Received August 14, 2008; Revised December 8, 2008; Accepted December 23, 2008; Online published February 5, 2009)

\begin{abstract}
The aims of this study were to develop an improved method using infrasound observations at multiple seismoacoustic arrays for locating small-magnitude surface explosions at regional distances and to apply the method to ground-truth blasting events for validation. The location method is based on a nonlinear grid search using the travel times and back azimuths of infrasonic signals generated from the surface explosions and on seismic parameters that are independently determined by routine seismic monitoring systems. Specifically, the method utilizes wind-corrected infrasonic azimuths in grid searching to constrain the grids according to nearness to feasibly real observations. Ground-truth events were recorded by a seismo-acoustic station temporarily operated inside an open-pit mine and then used to investigate the improvement by the location method. The method improved the locating of ground-truth events by approximately 50\% compared to the seismic location results. Surface explosions generating both seismic and infrasonic signals could be located independently by the seismic location, infrasonic-azimuth intersection, and seismo-acoustic location method, respectively. This method can be applied to automatic seismic/infrasonic monitoring systems as an additional location tool for explosion-induced seismic events, allowing for simultaneous monitoring for surface explosions and reduced risk of false location results.
\end{abstract}

Key words: Seismo-acoustic, surface explosion, grid search.

\section{Introduction}

Infrasound observation has recently been widely applied to clarify natural and anthropogenic phenomena producing low-frequency acoustics in the atmosphere, such as groundcoupled air waves from large earthquakes (Le Pichon et al., 2003; Watada et al., 2006), large bolides (P. G. Brown et al., 2002), and infrasound from accidental explosions (Evers and Haak, 2007). Infrasound technology is also important for monitoring possible nuclear explosions in the framework of the Comprehensive Nuclear-Test-Ban Treaty (Bedard and Georges, 2000).

One use of infrasound monitoring is to distinguish near-surface explosions from earthquakes. For example, the Korea Institute of Geoscience and Mineral Resources (KIGAM) operates multiple seismo-acoustic (infrasound) arrays with which it has identified $10 \%$ of the total number of seismic events $(\sim 3,000$ per year) occurring on the Korean Peninsula as surface explosions. Most of these explosions are concentrated in several epicentral regions. Field surveys confirmed that some epicenters in South Korea were at rock quarries, open-pit limestone mines, and construction sites (Che et al., 2002). Such discrimination of surface explosions has been an important tool for estimating the natural seismicity of specific regions.

Although infrasound observations can be used to discriminate anthropogenic explosions from natural events, the localization of explosion sources using only infrasound data

Copy right(c) The Society of Geomagnetism and Earth, Planetary and Space Sciences (SGEPSS); The Seismological Society of Japan; The Volcanological Society of Japan; The Geodetic Society of Japan; The Japanese Society for Planetary Sciences; TERRAPUB is not well developed compared to the conventional seismological location method mainly because infrasound propagation is strongly affected by dynamic atmospheric conditions. A common and easily used infrasonic source location method involves intersecting wind-corrected back azimuths measured at multiple infrasound arrays. However, the location result is expected to contain error. A more advanced infrasonic source location method using ground-coupled air waves from strong earthquakes (Le Pichon et al., 2003) is based on solving the inverse problem with a celerity model and apparent horizontal phase velocity. A known earthquake's origin time and epicenter coordinates make it possible to refine the localization of the source regions with the measured azimuth and slowness variation in infrasonic signals. However, the inverse procedure is only effective when realistic atmospheric profiles are available for a specific time and region so as to constrain the infrasonic phases and celerity. Therefore, this method is not appropriate for handling large numbers of events occurring in different areas and times, especially via an automatic process, if realistic atmospheric models are not available.

Modern seismological monitoring systems are gradually realizing lower detection thresholds that can detect smallmagnitude seismic events; such systems routinely produce large volumes of seismic reviews in real time. However, the location accuracy of small-magnitude seismic events is uncertain due to the low signal-to-noise ratio (SNR) and relatively small number of seismic observations.

The study reported here presents an improved location method for small-magnitude surface explosions that generate both seismic and infrasonic signals. The method makes full use of the seismic parameters of the explosions and 
infrasonic estimations of travel times and azimuths. To assess the performance of the method, we collected data on ground-truth events by operating a temporary seismoacoustic station inside an open-pit limestone mine, one of the most active regions generating both seismic and infrasonic signals in South Korea. Finally, we compared the location result with locations given by the seismological catalog, the infrasonic-azimuth intersection method, and the ground-truth information.

\section{Collection of Ground-truth Events}

Surface blasting activities at industrial mines are good examples of point sources producing impulsive infrasonic signals, where well-defined blasting information can be utilized to study characteristics of infrasound propagation in the atmosphere and to verify the infrasonic source location method. Figure 1(a) shows the locations of several seismic stations and seismo-acoustic arrays (BRDAR, CHNAR, KSGAR, KMPAR, and TJIAR) in South Korea. Figure 1(b) illustrates the distribution of seismic events around the eastern coast of South Korea from 2005 to 2006. Although the seismic magnitudes were generally $M_{\mathrm{L}} 2.0$ or lower, more than 900 events were reviewed by the Korea Earthquake Monitoring System (KEMS) during this period. Of all the events, those followed by distinct infrasonic signals detected by infrasound arrays could be definitely discriminated as surface explosions, not earthquakes; the former events are marked by yellow circles in the figure.

From a field survey, we identified a large open-pit limestone mine in the scattered distribution of these seismic events. This mine blasted several tons of explosives nearly every day and could be considered to be an infrasonic bell because many infrasonic signals from the mine have been recorded at the seismo-acoustic arrays since their initial installation. We thus inferred that other unclassified seismic events (white circles) around the mine location might be related to the blasting activities of the mine. We also concluded that the scattered distribution of seismic locations around the mine was related to seismic location errors resulting from the analysis of low SNR seismic data reflecting the sparse and narrow-azimuth distribution of seismic stations.

To collect ground-truth events at the mine, a temporary seismo-acoustic station was deployed approximately $300 \mathrm{~m}$ in front of the blasting point during July and August 2006. A three-component seismometer (CMG-40T1) and Chaparral M2 acoustic sensor were used to record near-field seismic and acoustic signals. The acoustic sensor was connected to a wind-noise reducer consisting of eight porous hoses in a radial pattern, approximately $16 \mathrm{~m}$ in diameter. Seismic and acoustic data were digitized at 100 samples per second. Horizontal distances from the blasting point to the seismo-acoustic arrays ranged from 128.2 to $383.8 \mathrm{~km}$.

During 46 days of sensor operation, the mine conducted 61 blastings, all delay-fired shots with explosive ranges of between 0.2 and 10.1 tons. The temporary station measured the near-field seismic and acoustic pressure changes of the blasts, thereby providing data to constrain the exact origin time and blast location. The mine office supplied yield information for each blast. From these near-field data, we

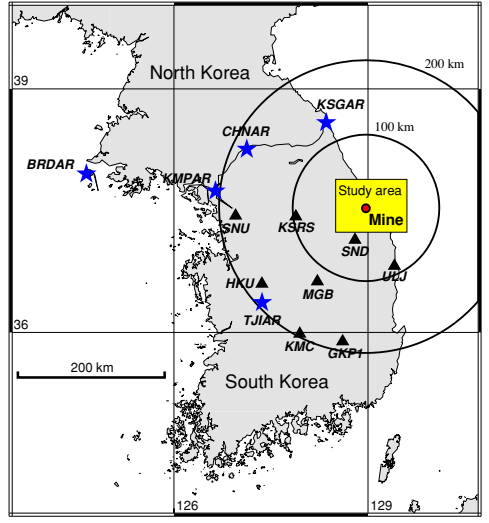

(a)

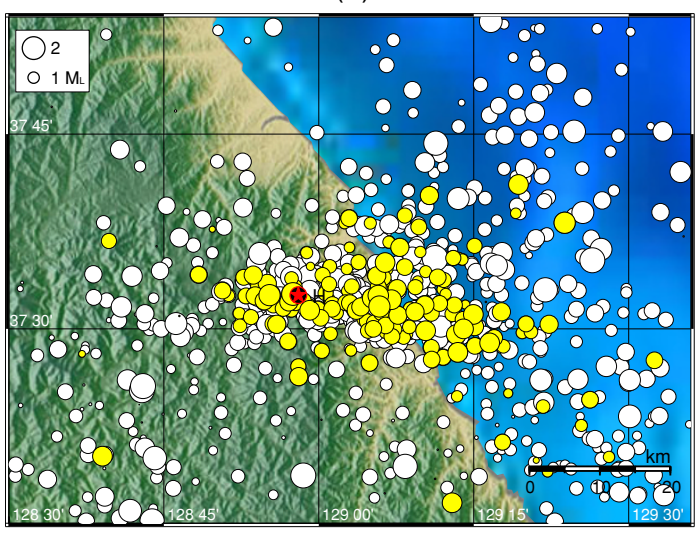

(b)

Fig. 1. (a) Locations of seismo-acoustic arrays (blue stars) and seismic stations (black triangles) near the study area, including the Korea Seismic Research Station (KSRS), which is the primary seismic station of the International Monitoring System. (b) Distribution of seismic events and an open-pit limestone mine $(\mathrm{H})$ in the study area.

could identify blasting activities of the mine from other unknown seismic activities that occurred during the period.

To analyze infrasonic signals recorded at distant seismoacoustic arrays, we used the progressive multichannel correlation (PMCC) method (Cansi, 1995) to identify coherent signals and estimate their wave parameters, such as back azimuth, apparent velocity, and arrival time (calculated by WinPMCC v2.1 with the following parameters: window length of $20 \mathrm{~s}$, frequency band in $1-5 \mathrm{~Hz}$ ). A search for an infrasound arrival was triggered by the seismic origin time within a broad range of infrasound phase velocities of $250-400 \mathrm{~m} / \mathrm{s}$. If the calculated azimuth of the infrasonic signal corresponded to the seismic epicenter of the blasting, then the infrasonic signals could be associated with the blast. Association between seismic and infrasonic signals was verified based on an acceptable arrival-time difference and back-azimuth difference within $\pm 10^{\circ}$. The backazimuth difference resulted from the resolution of the small infrasonic array and deflection by cross winds (Che et al., 2002). Of the 61 total blasts, infrasonic signals from 50 blasts were detected by at least one of the distant infrasound arrays, and infrasound from 27 blasts were detected by at least two arrays. In contrast, 36 blasts were seismologically detected as small-magnitude seismic events $\left(\sim 1.3 M_{\mathrm{L}}\right)$ by the KEMS. From the seismic and infrasonic detections, we selected 21 blasts for application of the seismo-acoustic lo- 
cation method described in the following section. These blasts were those detected by at least two infrasound arrays and the KEMS as seismic events.

\section{Result of the Seismo-acoustic Location Method}

A nonlinear grid-search method was applied to find the source location; the grid search was based on the observed travel times and azimuths of infrasonic signals at distant multiple arrays and on the seismic parameter that includes origin time and epicenter coordinate for a surface explosion reported in the seismological catalog. The minimization problem applied to the seismo-acoustic data is;

$R(x)=\left(\sum_{i=1}^{n}\left(\left(d_{i} / v-t_{i}\right)^{2}+C\left(D_{i} / v\right)^{2}\right) / n\right)^{1 / 2}$

where $n$ is the number of arrays detecting an infrasonic signal from a blasting, $d_{i}$ is the horizontal distance from a grid $(x)$ to the $i^{\text {th }}$ array, $v$ is the horizontal velocity of infrasound (celerity), and $t_{i}$ is the observed travel time to the $i^{\text {th }}$ array. $D_{i}$ is a normal distance from a grid point to the backazimuth line of the $i^{\text {th }}$ array. This metric term is included to penalize grid points located away from the wind-corrected infrasonic back azimuth according to nearness (distance) to the real observation. $C$ is a constant for weighting the second term in the equation relative to the travel-time residuals term. In the calculation, we first set grids $(\sim 1 \mathrm{~km})$ centered on the epicenter coordinate issued by the KEMS. At each grid node, predicted travel times to arrays were calculated by assuming a certain celerity value; these travel times were then compared with observed travel times $\left(t_{i}\right)$ measured from the seismic origin time to the initial pulse of infrasonic signals at arrays. The final location was determined with the minimum residual estimated using celerities varying from 0.23 to $0.31 \mathrm{~km} / \mathrm{s}$, a range that covers stratospheric $\left(I_{\mathrm{s}}\right)$ and thermospheric $\left(I_{\mathrm{t}}\right)$ infrasound phases (D. J. Brown et al., 2002).

Figure 2(a) shows an example of infrasonic waveforms recorded at the distant seismo-acoustic arrays generated from a 6 ton delay-fired shot at the mine. For this blast, all five seismo-acoustic arrays detected associated infrasonic signals, marked by yellow rectangles in the figure. The bottom two waveforms are near-field seismic and acoustic signals recorded at the temporary station. Figure 2(b) shows three locations for the blast obtained by the seismic location, infrasonic-azimuth intersection, and seismoacoustic location methods. The red star indicates the exact source point, and the white circle is the seismic location determined by the KEMS. White lines indicate infrasonic back azimuths calculated by PMCC at each array. The back azimuths were wind-corrected by empirical atmospheric models, HWM93/MSISE90, with the raytracing method (Garcés et al., 1998). Simply, intersection points from pairs of these azimuth lines could be estimated as sound source locations. To determine the most probable location, all intersections were weighted by the sine of the angle of intersection, and then a weighted average position for the most probable location for the event was determined (P. G. Brown et al., 2002) and plotted as a yellow circle. The red circle indicates a location result determined from

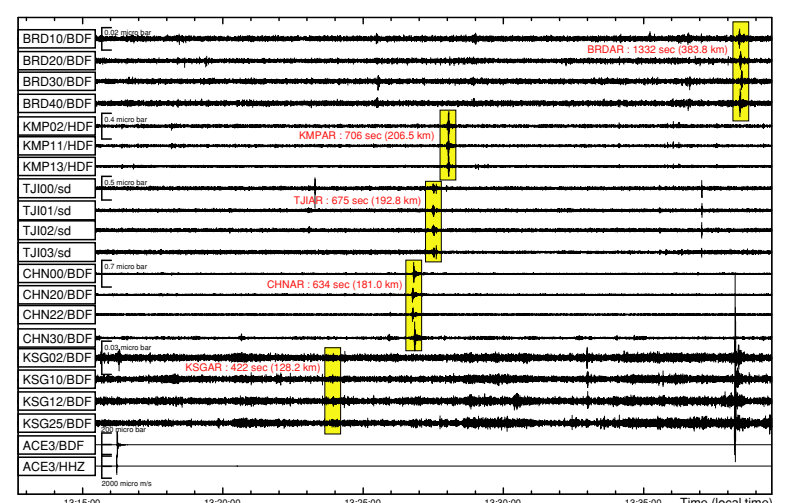

(a)

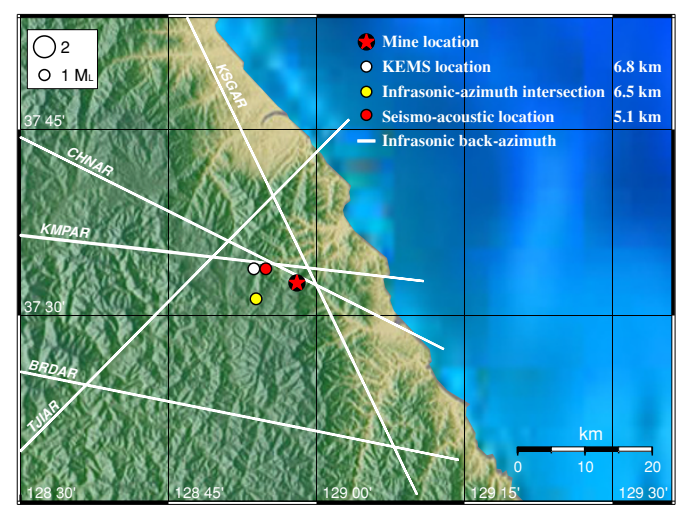

(b)

Fig. 2. (a) Infrasonic signals from 6 tons of ripple-firing shot, recorded at five distant infrasound arrays and near-field seismic (ACE3/HHZ) and acoustic (ACE3/BDF) signals. (b) Three location results and the exact mine location.

the grid-search method. For this event, the location difference of the seismo-acoustic location was $5.1 \mathrm{~km}$, which is slightly smaller than differences for other locations.

The seismo-acoustic location method was then applied to the 21 ground-truth events detected by the KEMS and by multiple infrasound arrays. Figure 3 summarizes the location results for these events using the three different location methods with the $90 \%$ confidence ellipse included for each method. The seismo-acoustic location had a mean location error of $5.7 \mathrm{~km}$, which represents a substantial improvement in location accuracy of $58.7 \%$ and $46.7 \%$ compared to the seismic location and infrasonic-azimuth intersection methods, respectively. In addition, the seismo-acoustic location method resulted in more concentrative distribution of locations into a source than other methods. The method obtained the best results when the constant $C$ (interval of $0.1-$ 1.0) was 0.4 , as shown in Fig. 3. When $C$ increased, the results resembled those of the infrasonic-azimuth intersection method. In contrast, when $C$ equaled 0.0 , grid searching involved only the use of travel-time residuals, and the mean location error was $12.4 \mathrm{~km}$.

In most cases of routine data processing, the KEMS uses data from the array KSRS supplemented with data from nearby seismic stations to locate the events. Since the KSRS is located about $96 \mathrm{~km}$ west of the mine shown in Fig. 1(a), a relatively large east-west uncertainty occurred in the event locations, as depicted in Fig. 3, due to picking errors for surface waves $\left(L_{\mathrm{g}}\right)$ in low SNR waveforms; this resulted 


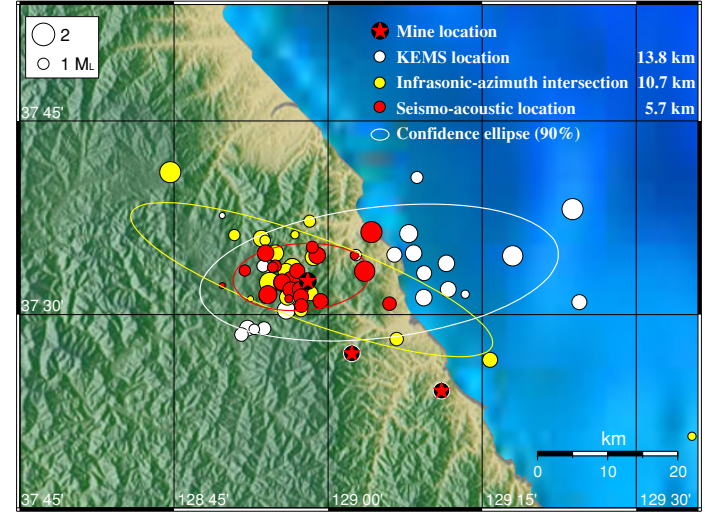

Fig. 3. Location results by the three methods for 21 ground-truth events.

in large distance errors in that direction. In the infrasonicazimuth intersection method, since probable locations were determined by a small number of azimuth lines mostly from two to three arrays, several events determined using poor azimuths showed large location errors. In addition, these locations were aligned in a northwest to southeast direction because most arrays were northwest of the mine, even though the azimuths were corrected for wind effect normal to the infrasound propagation. Deflection degrees by the cross winds were calculated within $-1.9^{\circ}$ to $2.7^{\circ}$ depending on the events and arrays.

\section{Conclusions}

A nonlinear grid-search method was used to improve the determination of surface explosion locations using infrasound records from seismo-acoustic arrays of several hundred kilometers. In addition to applying travel-times residuals, the method also used observed infrasonic azimuths to penalize grids according to nearness to the observations. Application of the method to ground-truth events showed that the method reduced location errors by about $50 \%$ compared to the routine seismic monitoring system and simple infrasonic-azimuth intersection method. This improvement can be explained by the "impulsive" arrival characteristic of infrasound and because infrasound waves are approximately 12-22 times slower than regional seismic waves $\left(P_{\mathrm{g}}\right.$ and $L_{\mathrm{g}}$ ). Thus, for the ground-truth events, the resulting travel-time differences scaled by slowness among impulsive infrasonic signals were smaller than those among seismic phases within low SNR, even though the travel time of infrasound might be affected by real sound velocity structures in the atmosphere. In general, the seismic location is more reliable than the location obtained by the seismo-acoustic method, if prepared with sufficient seismic data. However, in the case of small-magnitude surface explosions generating a weak seismic signal but impulsive infrasonic signal, the infrasonic location is comparable to the seismic location, or at least can help assess the result of the seismic location method. For instance, although the number of seismic stations used for each seismic location in KEMS was not exactly proportional to location accuracy, at least five seismic stations were needed for the location result comparable to the seismo-acoustic location under the distribution of seismic stations. Thus, we propose that this method can be applied to integrated seismic/infrasonic monitoring systems for small-magnitude surface explosions.

To obtain the seismo-acoustic location, the calculation procedure involved successive searching of varying celerity values, which were assumed to be equal value for all the arrays. Optimum locations were found with the celerity range of $275-305 \mathrm{~m} / \mathrm{s}$, but we experimentally measured a real celerity range of $287-293 \mathrm{~m} / \mathrm{s}$ based on the ground-truth information. These calculated and real celerity ranges strongly indicate that infrasonic signals from the blastings propagated as stratospheric phases (D. J. Brown et al., 2002) to all arrays located within regional distances.

This experiment was conducted during the summer. Thus, the real celerity range $(287-293 \mathrm{~m} / \mathrm{s})$ can be used as the initial value in the grid search for future applications. The real celerity, however, may vary by season; in particular, the season-dependent sound velocity in the atmosphere might cause a slower celerity in winter. Therefore, a long-term experiment covering all seasons at the mine will help clarify the seasonal variation of celerity in the midlatitude Northern Hemisphere, including the Korean Peninsula. This information will allow for the seismo-acoustic location method to be used in different seasons. In addition, a celerity dataset can be used with meteorological data to study the effect of local atmospheric conditions on infrasound propagation, such as the detectability, phase identification, and amplitude variation of infrasound at regional distances.

Acknowledgments. We would like to thank Dr. Le Pichon for support WinPMCC v2.1. Special thanks go to Mr. Kwan Kyo Chung, section manager of the mine office for his thoughtful supports during the experiment. This research was supported by the Basic Research Project of the Korea Institute of Geoscience and Mineral Resources (KIGAM) funded by the Ministry of Knowledge and Economy.

\section{References}

Bedard, A. J. and T. M. Georges, Atmospheric infrasound, Phys. Today, Mar., 32-37, 2000.

Brown, D. J., C. N. Katz, R. Le Bras, M. P. Flanagan, J. Wang, and A. K. Gault, Infrasonic signal detection and source location at the Prototype Data Centre, Pure Appl. Geophys., 159, 1081-1125, 2002.

Brown, P. G., R. Whitaker, D. O. ReVelle, and E. Tagliaferri, Multi-station infrasonic observations of two large bolides: signal interpretation and implications for monitoring of atmospheric explosions, Geophys. Res. Lett., 29, 1636, doi:10.1029/2001GL013778, 2002.

Cansi, Y., An automatic seismic event processing for detection and location: the PMCC method, Geophys. Res. Lett., 22, 1021-1024, 1995.

Che, I.-Y., M.-S. Jun, J.-S. Jeon, and K. D. Min, Analysis of local seismoacoustic events in the Korean Peninsula, Geophys. Res. Lett., 29, 1589, doi:10.1029/2001GL014060, 2002.

Evers, L. G. and H. W. Haak, Infrasonic forerunners: exceptionally fast acoustic phases, Geophys. Res. Lett., 34, L10806, doi:10. 1029/2007GL029353, 2007.

Garcés, M. A., R. A. Hansen, and K. G. Lindquist, Travel times for infrasonic waves propagating in a stratified atmosphere, Geophys. J. Int., 135, 255-263, 1998.

Le Pichon, A., J. Guilbert, M. Vallee, J. X. Dessa, and M. Ulziibat, Infrasonic imaging of the Kunlun Mountains for the great 2001 China earthquake, Geophys. Res. Lett., 30, 1814, doi:10.1029/2003GL017581, 2003.

Watada, S., T. Kunugi, K. Hirata, H. Sugioka, K. Nishida, S. Sekiguchi, J. Oikawa, Y. Tsuji, and H. Kanamori, Atmospheric pressure change associated with the 2003 Tokachi-Oki earthquake, Geophys. Res. Lett., 33, L24306, doi:10.1029/2006GL027967, 2006.

I.-Y. Che (e-mail: che10@kigam.re.kr), J. S. Shin, and I. B. Kang 